\title{
Optimization of Solar Module Encapsulant Lamination by Optical Constant Determination of Ethylene-Vinyl Acetate
}

\author{
Bing-Mau Chen, ${ }^{1}$ Cheng-Yu Peng, ${ }^{2}$ Ju-Lu Cho, ${ }^{1,2}$ and Glen Andrew Porter ${ }^{3}$ \\ ${ }^{1}$ Department of Opto-Electronic System Engineering, Minghsin University of Science and Technology, \\ No. 1 Xinxing Road, Xinfeng, Hsinchu 304, Taiwan \\ ${ }^{2}$ Green Energy and Environment Research Laboratories, Industrial Technology Research Institute, Hsinchu 310, Taiwan \\ ${ }^{3}$ Department of Electronics Engineering, National Kaohsiung University of Applied Sciences, 415 Chien Kung Road, \\ Kaohsiung 807, Taiwan \\ Correspondence should be addressed to Cheng-Yu Peng; pengcy@itri.org.tw
}

Received 21 July 2014; Revised 9 November 2014; Accepted 19 January 2015

Academic Editor: Harald Hoppe

Copyright (c) 2015 Bing-Mau Chen et al. This is an open access article distributed under the Creative Commons Attribution License, which permits unrestricted use, distribution, and reproduction in any medium, provided the original work is properly cited.

\begin{abstract}
This investigation elucidates the physical properties of ethylene-vinyl acetate (EVA) used in the lamination process of module encapsulation and the module performance from the optical transmission to the photoelectric power. In module encapsulation, the effects of the lamination parameters on the module performance, transmittance, and stack adhesion have been considered as they were found to influence the reliability of the module. The determination of the optical constants of EVA may serve as a nondestructive analytical method for optimizing the module encapsulation, on the basis of its effects on the optical transmittance, gel content, peel strength, and performance power.
\end{abstract}

\section{Introduction}

Many approaches, including the use of particular cell materials $[1,2]$, the design of cell structures [3, 4], the use of modules $[5,6]$, and the concentration PV collector systems $[7,8]$, have been developed to increase the efficiency of the generation of solar electricity. However, few studies have addressed the effects of the solar module encapsulation, which has been widely applied and typically involves optical and electrical losses. The EVA encapsulation using ethylene vinyl acetate copolymer as a pottant mainly determines the optical loss of irradiance through the module structure, which affects the photogenerated current related to the output power [9]. Therefore, the factors affecting the optical, electrical, and adhesive properties and parameters such as the temperature and duration of the EVA lamination process are the major concerns which determine the transmittance, the adhesion strength, and the output power of the photovoltaic module. Moreover, the major bottleneck in solar module technology concerns how to boost the collection of photo flux by using a highly transparent module structure or by optimizing the quality of the EVA in the lamination process.
Using the common module structure of glass/EVA/cell/ EVA/backsheet as an example, we find that such modules have been tested in hot environments, both dry and humid, in which EVA discoloration has been identified as well [10]. The discoloration of EVA, ranging from yellow to dark brown, has been associated with performance losses and issues of reliability. Therefore, the primary goal of this study is to explicate the variability of the key characteristics: the optical transmittance, the peel strength of EVA, and the performance power, in relation to the module lamination process. The secondary purpose concerns the quality control of the PV module during the process of EVA encapsulation, by determining the optical constants. The relationships between the optical constants of the EVA film and the lamination temperature and duration can be derived from both the transmittance and reflectance spectra. This investigation presents the relationships between the optical constants, including the refractive index and extinction coefficient, the optical transmittance spectrum, the peel strength of EVA, and the electrical power of the solar cell against the EVA lamination time and temperature. 


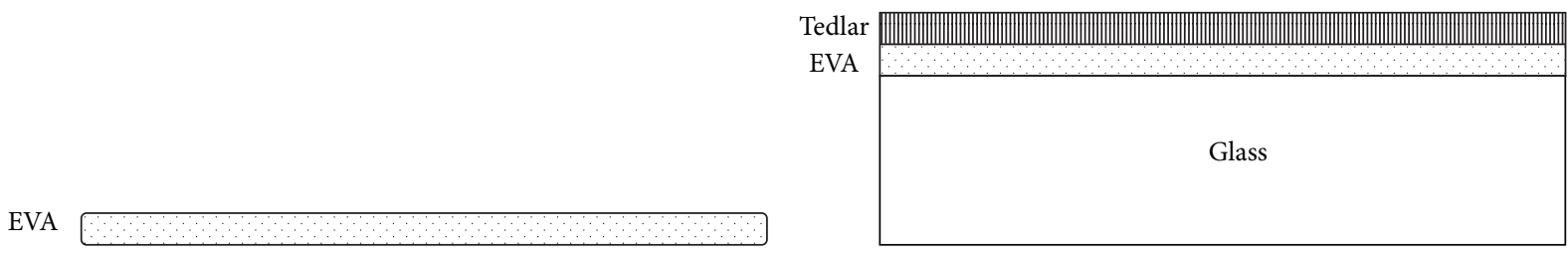

(a)

(b)

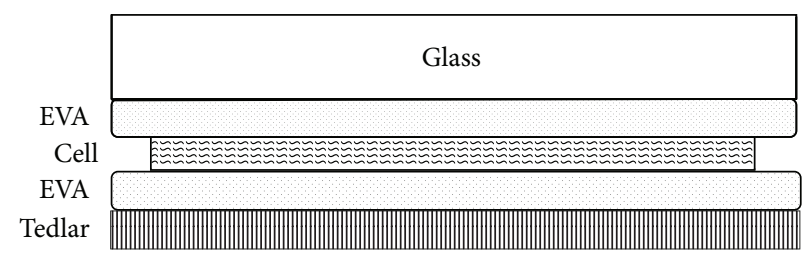

(c)

FIGURE 1: Lamination structures: (a) EVA film for optical transmittance testing, (b) glass/EVA/Tedlar for peel testing, and (c) glass/EVA/cell/ EVA/Tedlar for power testing.

\begin{tabular}{|l|l|l|}
\hline \multicolumn{3}{|c|}{ Fluorocarbon film } \\
\hline Spacer & End \\
& Fluorocarbon film \\
\hline
\end{tabular}

(a)

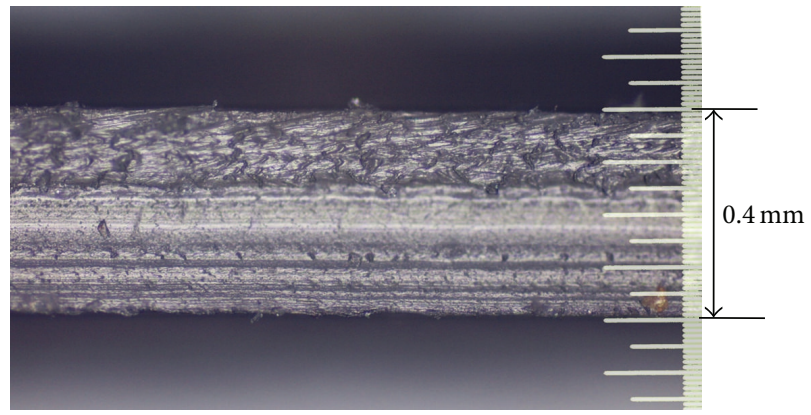

(b)

FIgURE 2: (a) The configuration of EVA film preparing. (b) The EVA film was observed by optical microscope.

\section{Experimental}

Three test structures for the EVA film were prepared for the test procedures, as shown in Figure 1, where a fast curing EVA was used to form films with a thickness of $0.4 \mathrm{~mm}$. Figure 1(a) portrays the EVA film made for the optical transmission tests. The EVA film was prepared by sandwiching the precured polymer between two flat fluorocarbon films with $0.4 \mathrm{~mm}$ spacers being used to control the resulting EVA film thickness. After curing, the fluorocarbon films and spacers were removed. The fluorocarbon film molds produced a surface profile with the flat morphology needed to avoid a detraction from the transmission due to light scattering, as shown in Figure 2(a). Following the fabrication, the surface flatness and film thickness of the EVA were measured with digital calipers and observed by an optical microscope, respectively, as shown in Figure 2(b). The glass/EVA/Tedlar structure was used in the peel strength test, and the glass/EVA/cell/EVA/Tedlar structure was used in the electrical power testing, and they are displayed in Figures 1(b) and 1(c), respectively. The textured glass superstrate used was a double-side textured antireflective glass from Saint-Gobain (Albarino S type) (http://www.nitrasklo.sk/dokumenty-nastiahnutie/sgg-albarino-prospekt.pdf). The encapsulant processes for these three EVA film samples were kept consistent.
For example, the modules were mounted on the heated surface of the laminator using a common package structure (glass/encapsulant/solar cell/encapsulant/highly reflective backsheet). The various modules were formed using various lamination times and temperatures known to optimize the fabrication processing. According to the pressing process, the solar module structure was placed into the laminator at $150^{\circ} \mathrm{C}$ and a vacuum in $10^{-2}$ torr was drawn from the upper and lower chambers for 8 minutes. Next, the vacuum of the upper chamber was held for 7 minutes to control the lamination time, and then the solar module package structure was optimally pressed and sealed. Likewise, the other laminated modules can be fabricated by employing the various lamination times and the pressing processes compatible with any currently popular lamination machinery.

The lamination temperature was designated in the range between 90 and $170^{\circ} \mathrm{C}$, in the experiments that involved the NPC laminator (NPC Corp. LM-SA-170 * 260-S). The optical transmittance spectrum of the EVA film was measured using a spectrometer instrument with a wavelength $(\lambda)$ resolution of $\pm 1 \mathrm{~nm}$ and an absolute photometric accuracy of $\pm 0.2 \%$ in the ultraviolet/visible range (Perkin Elmer Corp. LAMBDA750). The spectrometer measurement followed the standard ASTM D1003 procedure for detecting the direct and diffuse transmittance of light, within an incidence of 
TABLE 1: The data for the lamination temperature, the power performance, the optical transmittance, the peel strength, the refractive index, and the gel content for the EVA lamination of solar modules.

\begin{tabular}{|c|c|c|c|c|c|}
\hline $\begin{array}{l}\text { Lamination } \\
\text { temperature } \\
\left({ }^{\circ} \mathrm{C}\right)\end{array}$ & $\begin{array}{l}\text { Power difference } \\
\text { ratio }(\%)\end{array}$ & $\begin{array}{l}\text { Optical transmittance } \\
\quad(\%)(580 \mathrm{~nm})\end{array}$ & $\begin{array}{l}\text { Peel strength } \\
(\mathrm{N} / \mathrm{cm})\end{array}$ & $\begin{array}{c}\text { Refractive } \\
\text { index }(580 \mathrm{~nm})\end{array}$ & $\begin{array}{l}\text { Gel content } \\
\quad(\%)\end{array}$ \\
\hline 90 & $8.08 \pm 0.3$ & $89.67 \pm 0.2$ & $0.5 \pm 0.5$ & $1.60 \pm 0.005$ & $0.39 \pm 8$ \\
\hline 110 & $8.52 \pm 0.3$ & $89.80 \pm 0.2$ & $0.55 \pm 0.5$ & $1.59 \pm 0.005$ & $0.63 \pm 8$ \\
\hline 130 & $8.52 \pm 0.3$ & $90.04 \pm 0.2$ & $1.97 \pm 0.5$ & $1.59 \pm 0.005$ & $1.53 \pm 8$ \\
\hline 150 & $9.53 \pm 0.3$ & $91.35 \pm 0.2$ & $9.6 \pm 0.5$ & $1.54 \pm 0.005$ & $75.89 \pm 4$ \\
\hline 170 & $10.39 \pm 0.3$ & $91.90 \pm 0.2$ & $6.2 \pm 0.5$ & $1.50 \pm 0.005$ & $92.0 \pm 4$ \\
\hline
\end{tabular}

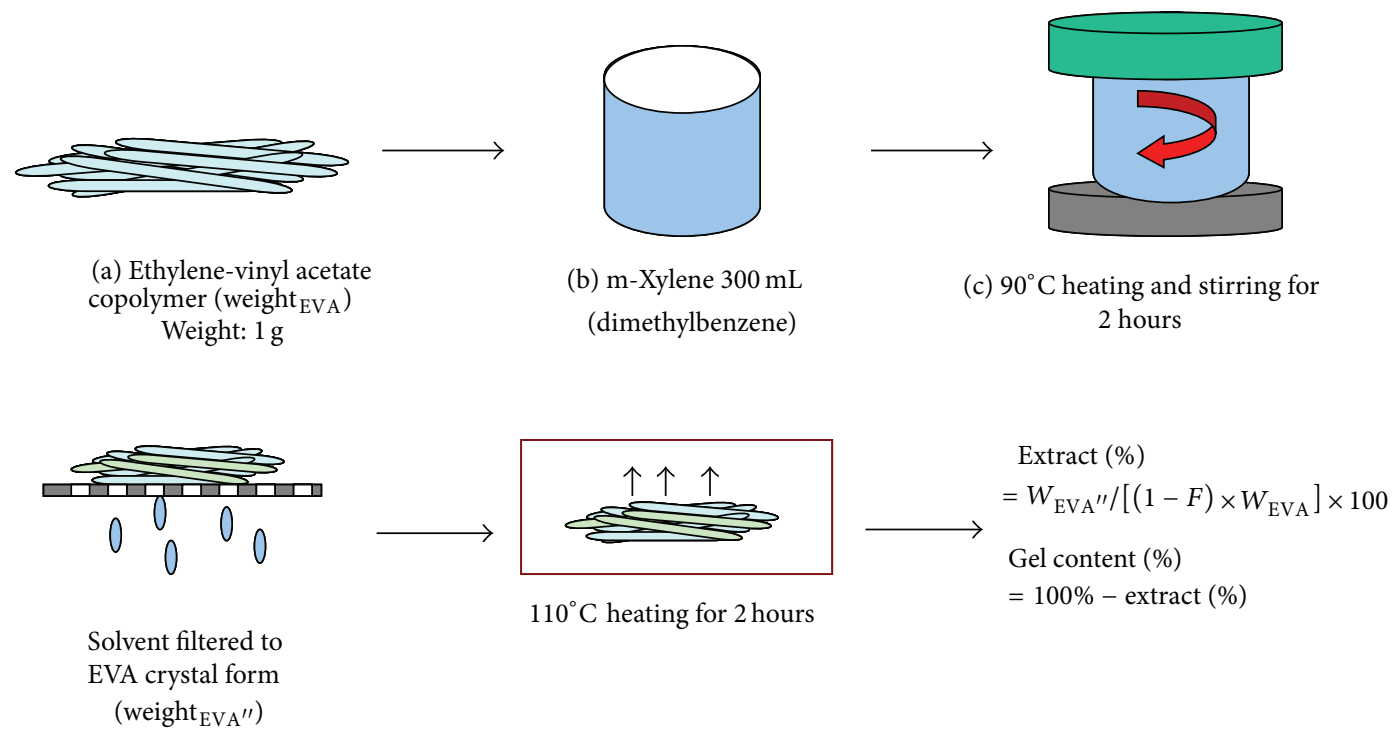

$F=$ fraction of filtered solvent in the polyethylene compound

FIgURE 3: The experimental process of gel content measurement.

$5^{\circ}$ by an integrating sphere. The spectrometer readings were normalized for each measurement by a standard calibration (NIST SRM 930), using a sample of BK7 glass. To determine the optical constants, the transmittance is measured through three kinds of thicknesses, $0.4,1.2$, and $2.0 \mathrm{~mm}$. Three thicknesses prepared with known spacers, as shown in Figure 2(a), helped determine the accuracy of the measured optical constants without a reflectance measurement.

To probe the optical properties of the EVA film following lamination, the optical constants, the refractive index, and the extinction coefficient of the EVA laminated under different parameters were determined from both the transmittance and the reflectance spectra. The material dispersion model, based on the Cauchy theory [11], was applied to model the coupling, the effect of both sides of the EVA substrate in which multiple reflections and transmissions take place.

The gel content of the cross-linking EVA was measured according to the standard ASTM D2765-11 procedure using a xylene solution, as shown in Figure 3. The gel content can be determined by extracting the weight ratio between the ethylene-vinyl acetate copolymer and a solvent filtered through the EVA crystal form. The peel strength of the structure (glass/EVA/backsheet) was measured by the standard ASTM D903 procedure, using an appropriate peel testing instrument (MOGR Corp. L009). The adhesion of EVA to glass is measured at a peel angle of $90^{\circ}$ [12], a peel rate of $36 \mathrm{~cm} / \mathrm{min}$, a peel distance of $10 \mathrm{~cm}$, and a peel width of $1 \mathrm{~cm}$, under the laboratory conditions (humidity $=50 \pm 2 \%$ and temperature $=23 \pm 1^{\circ} \mathrm{C}$ ). The electrical power (IV curve) of the solar cell was measured using a flash solar simulator (BERGER Corp. PSS30).

\section{Results and Discussion}

Table 1 presents the data for the lamination temperature, the power performance, the optical transmittance, the peel strength, the refractive index, and the gel content, in the module lamination process. The optical transmittance, power difference ratio, and gel content increased with lamination temperature. The refractive index decreased with lamination temperature. The peel strength of EVA increased with the lamination temperature up to $150^{\circ} \mathrm{C}$.

The optical transmittance of EVA film with a thickness of $0.4 \mathrm{~mm}$ increased with the lamination time, when 


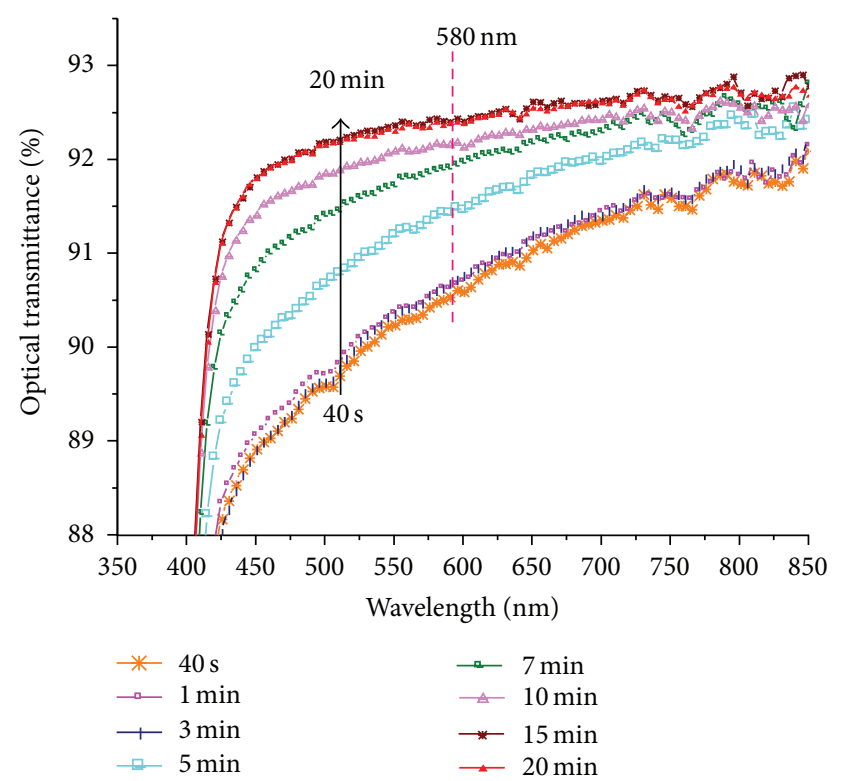

FIgURE 4: Transmittance versus lamination time at the lamination temperature of $150^{\circ} \mathrm{C}$.

the lamination temperature was fixed at $150^{\circ} \mathrm{C}$, as presented in Figure 4. When the lamination time exceeded $7 \mathrm{~min}$, the transmittance of the EVA was relatively good. But when the lamination time was between 15 and 20 minutes, the optical transmittance of the EVA film was over $92 \%$ (at $\lambda=580 \mathrm{~nm}$ ). The transmittance declined slightly as the lamination time increased past 15 minutes, indicating that such a period of lamination exceeds the ideal duration. Based on an absolute transmittance repeatability of $\pm 0.2 \%$, the deviation of the transmittance data, ranging from 20 seconds to 20 minutes, at a wavelength of $580 \mathrm{~nm}$, was $1.98 \%$.

The transmission spectrum of the EVA film increased with the lamination temperature when the duration was fixed at 7 minutes, as displayed in Figure 5. The transmittance of the EVA films changed by $2.2 \%$ as the lamination temperature increased from 90 to $170^{\circ} \mathrm{C}$ (at $\lambda=580 \mathrm{~nm}$ ).

When the lamination temperature was fixed at $150^{\circ} \mathrm{C}$, the refractive index decreased by $0.09(\lambda=580 \mathrm{~nm})$, as the lamination time was increased from 3 to 10 minutes, as presented in Figure 6. The refractive index range can thus be tuned by changing the period of lamination from 3 to 7 minutes. The slope of the refractive index to the lamination time showed a gentler change as the lamination time increased over 7 minutes, revealing that the degree of cross-linking in the EVA was slowly approaching saturation.

The dependence of the optical constants of the EVA films on the lamination temperature was derived from the transmittance curve when the lamination time was fixed at 7 minutes, as displayed in Figure 7. The refractive index declined by $0.1(\lambda=580 \mathrm{~nm})$ as the lamination temperature increased from 90 to $170^{\circ} \mathrm{C}$. The refractive index declined significantly as the lamination temperature increased from 130 to $170^{\circ} \mathrm{C}$. The extinction coefficient under these lamination conditions was less than $3.27 \times 10^{-10}$. These results indicate

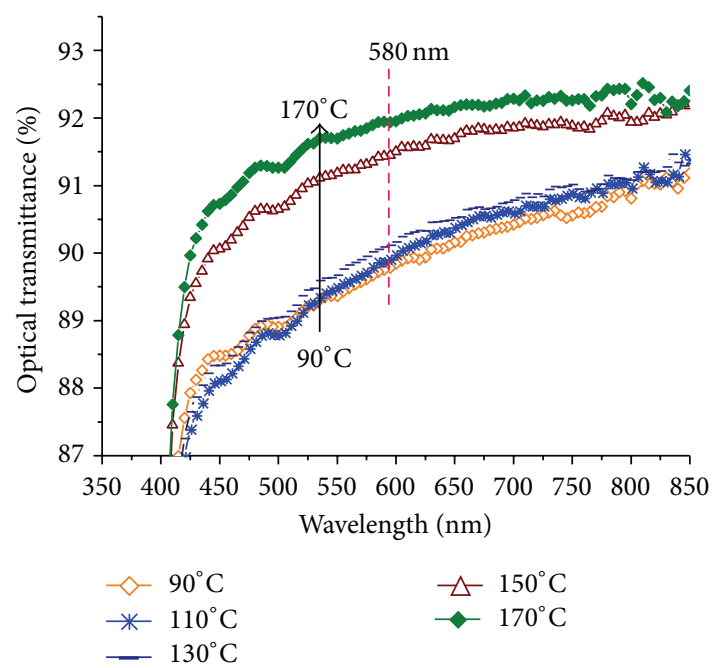

FIGURE 5: Transmittance as a function of lamination temperature at the lamination time of 7 minutes.

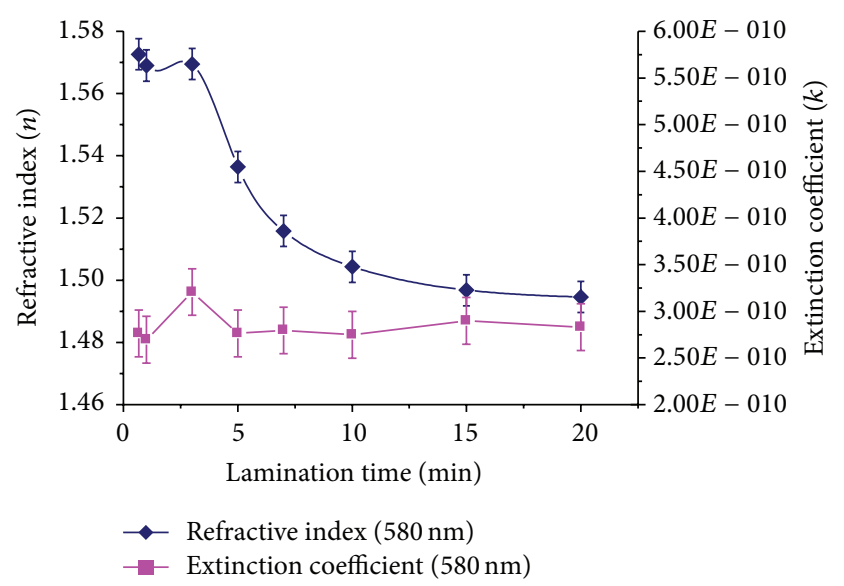

FIgURE 6: The optical constants of EVA for various lamination times, at a lamination temperature of $150^{\circ} \mathrm{C}$, and a wavelength of $580 \mathrm{~nm}$.

that the refractive index of EVA decreases as the cross-linking gradually becomes saturated as the lamination temperature was increased to $150^{\circ} \mathrm{C}$.

Figure 8(a) plots the transmittance and refractive index $(\lambda=580 \mathrm{~nm})$ as a function of the lamination time at a fixed lamination temperature of $150^{\circ} \mathrm{C}$. As the lamination time increased from 3 to 7 minutes, the refractive index declined rapidly. In contrast, the transmittance increased rapidly with a longer lamination time. When the lamination time increased beyond 7 minutes, the refractive index began to decrease slowly. Similarly, the transmittance increased slowly in proportion to the lamination time, growing $1.3 \%$ from 3 to 7 minutes. Figure 8(b) plots the transmittance and refractive index at a wavelength of $580 \mathrm{~nm}$, versus the lamination temperature for a fixed 7-minute lamination time. As the lamination temperature increased from 90 to $130^{\circ} \mathrm{C}$, the refractive index seemed to remain constant. But then, as the lamination temperature increased from 130 to $170^{\circ} \mathrm{C}$, the refractive index declined. On the contrary, the transmittance 


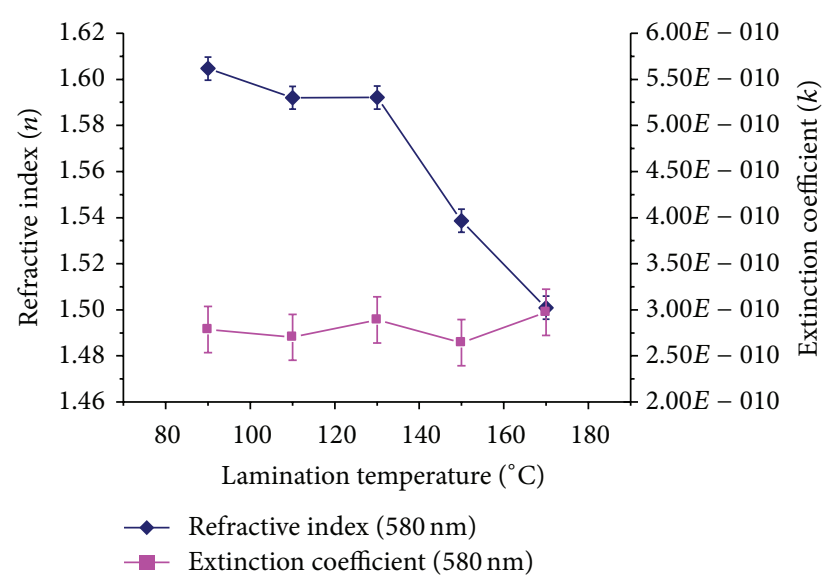

FIGURE 7: The optical constants of EVA made at various lamination temperatures, a consistent lamination time of 7 minutes, and wavelength of $580 \mathrm{~nm}$.

increased rapidly by extending the lamination time. The transmittance changed by $2.23 \%$ as the lamination temperature increased from 90 to $170^{\circ} \mathrm{C}$.

According to the material dispersion model, based on the Cauchy theory, the change in refractive index during lamination could be explained by the following mechanism. Here, two materials are interfused, the EVA and the crosslinking agent. The refractive index is estimated with respect to the mixing of crystalline materials and was analyzed by the effective medium approach of the Bruggeman model [13]. The gel contents of the EVA change with the lamination time, as the cross-linking changes the state from linear to long chains, thus leading to a decrease in the EVA polycrystallinity and an increase in the transmission $[14,15]$.

Comparing the changes in the refractive index, it is evident that the lamination temperature affected the optical transmittance of EVA more than the lamination time. Nevertheless, if either the lamination time or the temperature produced an EVA state close to saturation, then the optical transmittance and the refractive index remained stable. These results suggest that the optical loss associated with the PV module lamination process can be reduced by tuning the EVA processing parameters to produce a desired refractive index. Hence, choosing the appropriate ratio of encapsulation monomers and presetting the ideal EVA index of refraction can increase the transmission of light within the solar cell modules.

Figure 9(a) plots the refractive index, the gel content, and the peel strength of the EVA against the lamination time at a fixed lamination temperature of $150^{\circ} \mathrm{C}$. As the lamination time increased from 40 seconds to 7 minutes, the peel strength increased from 0.05 to $10.5 \mathrm{~N} / \mathrm{cm}$; then, as the lamination time increased beyond 7 minutes, the peel strength decreased. In the meantime, the gel content increased with the lamination time, having a similar trend as the peel strength with respect to the lamination time.

As shown in Figure 9(a), the refractive index of the EVA declined rapidly as the lamination time increased from 3 to 7 minutes. In contrast, the peel strength of EVA increased rapidly with the lamination time. Then, when the lamination time increased beyond 7 minutes, the refractive index fell slowly, but the peel strength of the EVA declined. The trend in gel content shows a stable value when the lamination time increased from 10 to 20 minutes. Comparing the results of the peel strength and the gel content with the lamination time, a qualified peel strength of EVA was not achieved until the EVA gel content neared $75 \%$.

Figure 9(b) plots the refractive index $(\lambda=580 \mathrm{~nm})$, peel strength, and gel content against the lamination temperature for a fixed lamination time of 7 minutes. A relatively constant refractive index of EVA is depicted at lamination temperatures under $130^{\circ} \mathrm{C}$, indicating that there was no curing reaction taking place and resulting in a low gel content. Above $130^{\circ} \mathrm{C}$ and until $170^{\circ} \mathrm{C}$, the refractive index decreased rapidly.

The peel strength of the adhesive structure of the solar module increased rapidly, from 0.04 to $9.6 \mathrm{~N} / \mathrm{cm}$, with a lamination temperature rising from 90 to $150^{\circ} \mathrm{C}$, for a fixed lamination time of 7 minutes. The peel strength was proportional to gel content when the lamination temperature was between 90 and $150^{\circ} \mathrm{C}$. Moreover, the industrial criterion for both the adhesion and the gel content $(>50 \mathrm{~N} / \mathrm{cm}$ and $>75 \%$, resp.) can be realized when the lamination temperature is above $150^{\circ} \mathrm{C}$.

With respect to the refractive index, the peel strength increased rapidly when the refractive index of the EVA decreased during the lamination process, and the maximum EVA peel strength occurred when the refractive index of EVA was near the midvalue between the initial and the stable refractive index in the lamination process. For example, the EVA had a maximum peel strength when the lamination time was between 5 and 7 minutes, while the refractive index of EVA was near the midvalue with the lamination time, as shown in Figure 9(a). A similar behavior can be found in Figure 9(b). The EVA has a maximum peel strength when the lamination temperature is 150 to $170^{\circ} \mathrm{C}$, and the refractive index is also near a midvalue with the lamination temperature.

The peel strength relates to two factors: (1) the adhesion of the silane agent to the glass or backsheet and (2) the cross-linking agent produced during the curing reaction. By increasing the EVA lamination temperature, oligomeric vinyl silanes enact the adhesion reaction with the glass or backsheet, and, simultaneously, the peroxide catalyst initiates the cross-linking reaction, thereby achieving a stronger peel strength.

Based on parallel studies using differential scanning calorimetry (DSC), the peroxide catalyst of the EVA film usually begins curing at $120^{\circ} \mathrm{C}$, and the cross-linking reaction serves to increase the crystallinity of the EVA, yielding a higher transmission. The above results indicate that when the lamination temperature is above a critical temperature, for example, $\sim 135^{\circ} \mathrm{C}$ for the typical "fast-curing" EVA, the curing reaction induces cross-linking [16]. When processed in the $90 \sim 130^{\circ} \mathrm{C}$ range, the heating only serves to melt the EVA film for lamination. The reaction temperature observed in our work could be higher because antioxidants are generally added to the commercial EVA formulation to avoid thermal degradation below the curing temperature of $180^{\circ} \mathrm{C}$. 


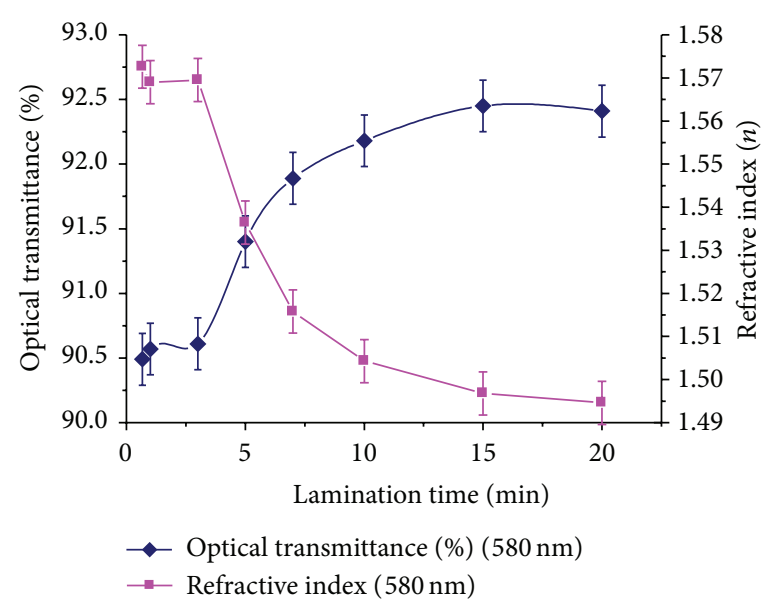

(a)

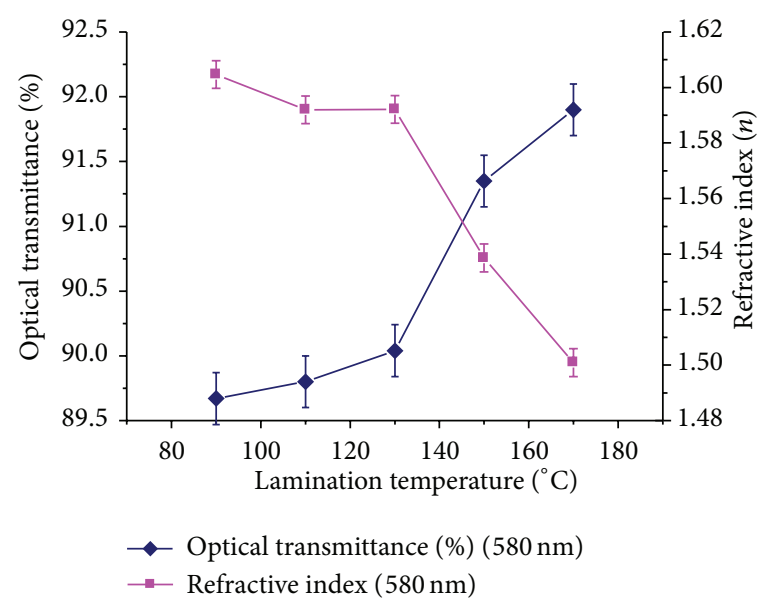

(b)

FIgURE 8: (a) The refractive index and optical transmittance of EVA versus the lamination time at a fixed lamination temperature of $150^{\circ} \mathrm{C}$. (b) The refractive index and optical transmittance of EVA as functions of the lamination temperature for a fixed lamination time of 7 minutes.

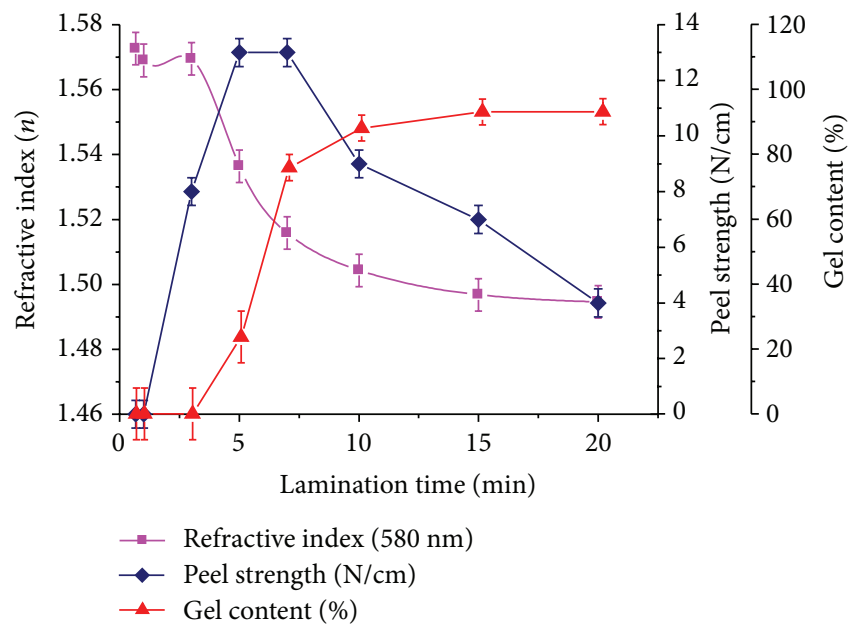

(a)

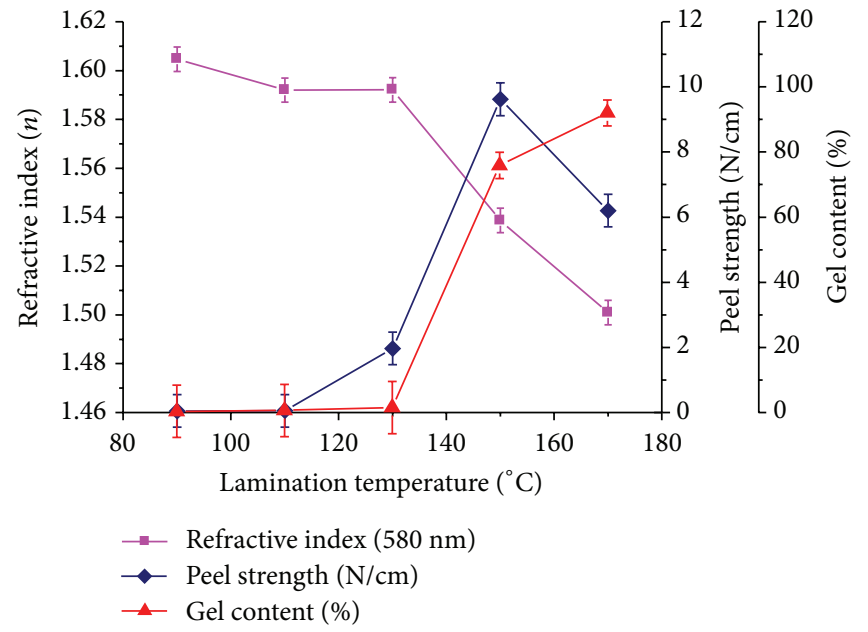

(b)

Figure 9: (a) The refractive index, gel content, and peel strength of EVA versus the lamination time at a fixed lamination temperature of $150^{\circ} \mathrm{C}$. (b) The refractive index, gel content, and peel strength of EVA as a function of the lamination temperature for a fixed lamination time of 7 minutes.

If the antioxidants work to avoid curing, it implies that the chemically reduced EVA exhibits lower optical transmittance and a higher refractive index.

The above results indicate that the refractive index changes as the gel content increases with lamination time and temperature, which suggests that the method of determining the refractive index of EVA could also be used to detect the gel content of EVA. The results also indicate that the peel strength increased rapidly as the gel content of EVA increased before saturation, and the qualified peel strength of EVA occurred when the gel content of EVA was near $75 \%$. Therefore, either the refractive index or the gel content could be used to estimate the adhesion quality of EVA, but it is especially noteworthy to mention that measuring the gel content is a destructive and time-consuming testing method, whereas measuring the refractive index is nondestructive. So in conclusion, observing the change in refractive index during the lamination process could be a method to monitor the gel content of EVA and control the quality of the module during fabrication.

Figure 10 compares the relationship between the power difference ratio $\left(\triangle P / P_{b}\right)$ and the optical transmittance with the lamination temperature, where $\Delta P$ denotes the difference between the maximum output powers of the solar cell before $\left(P_{b}\right)$ and after $\left(P_{a}\right)$ the lamination process. The optical transmittance increased with lamination temperature, as did the power difference ratio, implying that increasing the transmittance of the EVA encapsulation increases the efficiency of the solar module. 


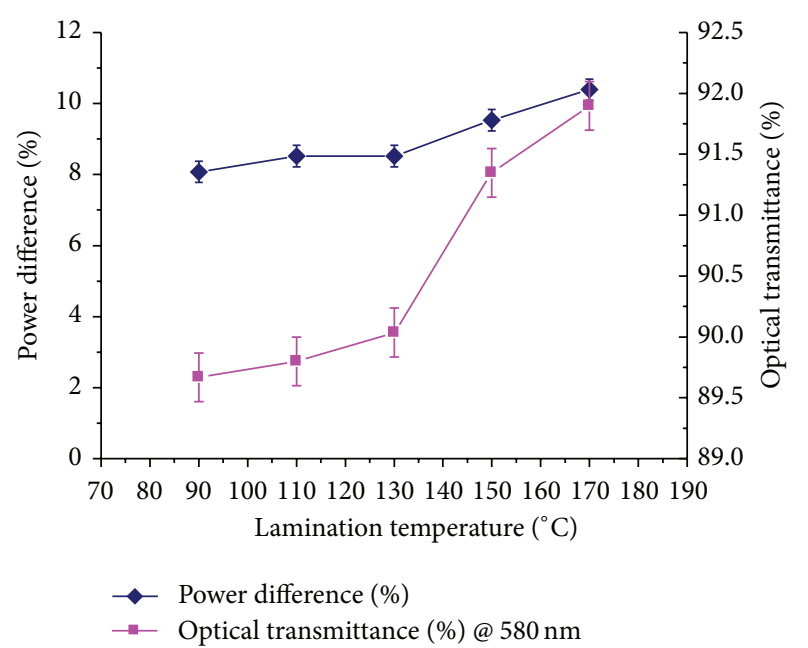

FIGURE 10: The power difference ratio and the optical transmittance as functions of the lamination temperature.

\section{Conclusions}

In this study, the refractive index of an EVA encapsulation was utilized to determine the differences in the physical properties of the solar cell associated with lamination temperatures of 90 and $170^{\circ} \mathrm{C}$ and durations of 40 seconds and 10 minutes. The optical transmittance, as analyzed by the optical constant determination, is a significant indicator for both the adhesion reaction and the cross-linking reaction. The curing time and temperature of the EVA can be used as a nondestructive testing method for estimating the EVA gel content. The EVA lamination parameters having a time greater than 10 minutes and a temperature greater than $150^{\circ} \mathrm{C}$ accurately indicate the gel content greater than $75 \%$ and a peel strength above $50 \mathrm{~N} / \mathrm{cm}$. Determining the refractive index of EVA might provide quality control information concerning the EVA encapsulation, to be used in conjunction with other data on the optical transmittance, peel strength, and power performance, which can be engineered to optimize the encapsulant of the solar module.

\section{Conflict of Interests}

The authors declare that there is no conflict of interests regarding the publication of this paper.

\section{Acknowledgment}

The authors would like to thank the Taiwan Bureau of Energy for the financial support of this research.

\section{References}

[1] Y. Ogomi, Y. Kashiwa, Y. Noma et al., "Photovoltaic performance of dye-sensitized solar cells stained with black dye under pressurized condition and mechanism for high efficiency," Solar Energy Materials and Solar Cells, vol. 93, no. 6-7, pp. 1009-1012, 2009.
[2] K. Hartman, M. Bertoni, J. Serdy, and T. Buonassisi, "Dislocation density reduction in multicrystalline silicon solar cell material by high temperature annealing," Applied Physics Letters, vol. 93, no. 12, Article ID 122108, 2008.

[3] P. Matheu, S. H. Lim, D. Derkacs, C. McPheeters, and E. T. $\mathrm{Yu}$, "Metal and dielectric nanoparticle scattering for improved optical absorption in photovoltaic devices," Applied Physics Letters, vol. 93, no. 11, Article ID 113108, 2008.

[4] L. Tsakalakos, J. Balch, J. Fronheiser, B. A. Korevaar, O. Sulima, and J. Rand, "Silicon nanowire solar cells", Applied Physics Letters, vol. 91, no. 23, Article ID 233117, 2007.

[5] A. Freundlich, A. Fotkatzikis, L. Bhusal et al., "III-V dilute nitride-based multi-quantum well solar cell," Journal of Crystal Growth, vol. 301-302, pp. 993-996, 2007.

[6] M. Biancardo, K. Taira, N. Kogo et al., "Characterization of microspherical semi-transparent solar cells and modules," Solar Energy, vol. 81, no. 6, pp. 711-716, 2007.

[7] K. Ryu, J.-G. Rhee, K.-M. Park, and J. Kim, “Concept and design of modular Fresnel lenses for concentration solar PV system," Solar Energy, vol. 80, no. 12, pp. 1580-1587, 2006.

[8] K. K. Chong and C. W. Wong, "General formula for on-axis sun-tracking system and its application in improving tracking accuracy of solar collector," Solar Energy, vol. 83, no. 3, pp. 298305, 2009.

[9] A. W. Czanderna and F. J. Pern, "Encapsulation of PV modules using ethylene vinyl acetate copolymer as a pottant: a critical review," Solar Energy Materials and Solar Cells, vol. 43, no. 2, pp. 101-181, 1996.

[10] F. J. Pern, "Factors that affect the EVA encapsulant discoloration rate upon accelerated exposure," Solar Energy Materials and Solar Cells, vol. 41-42, pp. 587-615, 1996.

[11] M. T. Othman, J. A. Lubguban, A. A. Lubguban et al., "Characterization of porous low-k films using variable angle spectroscopic ellipsometry," Journal of Applied Physics, vol. 99, no. 8, Article ID 083503, 2006.

[12] G. J. Jorgensen, K. M. Terwilliger, J. A. DelCueto et al., "Moisture transport, adhesion, and corrosion protection of PV module packaging materials," Solar Energy Materials and Solar Cells, vol. 90, no. 16, pp. 2739-2775, 2006.

[13] G. A. Niklasson, C. G. Granqvist, and O. Hunderi, "Effective medium models for the optical properties of inhomogeneous materials," Applied Optics, vol. 20, no. 1, pp. 26-30, 1981.

[14] C. Hirschl, M. Biebl-Rydlo, M. DeBiasio et al., "Determining the degree of crosslinking of ethylene vinyl acetate photovoltaic module encapsulants-a Comparative Study," Solar Energy Materials and Solar Cells, vol. 116, pp. 203-218, 2013.

[15] H.-Y. Li, L.-E. Perret-Aebi, R. Théron, C. Ballif, Y. Luo, and R. F. M. Lange, "Optical transmission as a fast and non-destructive tool for determination of ethylene-co-vinyl acetate curing state in photovoltaic modules," Progress in Photovoltaics: Research and Applications, vol. 21, no. 2, pp. 187-194, 2013.

[16] K. Agroui, A. Maallemi, M. Boumaour, G. Collins, and M. Salama, "Thermal stability of slow and fast cure EVA encapsulant material for photovoltaic module manufacturing process," Solar Energy Materials and Solar Cells, vol. 90, no. 15, pp. 25092514,2006 

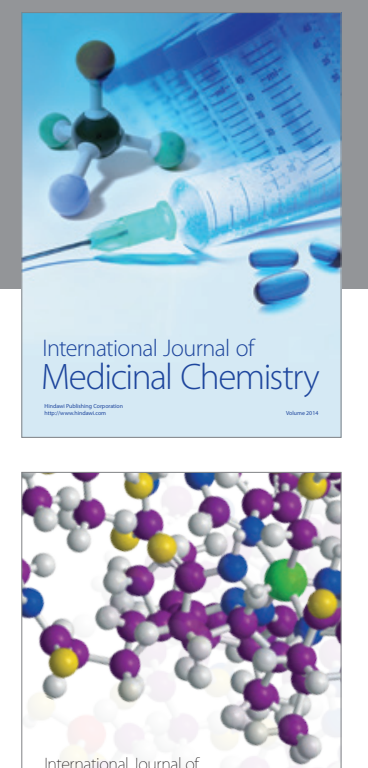

\section{Carbohydrate} Chemistry

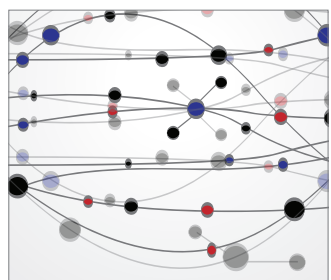

The Scientific World Journal
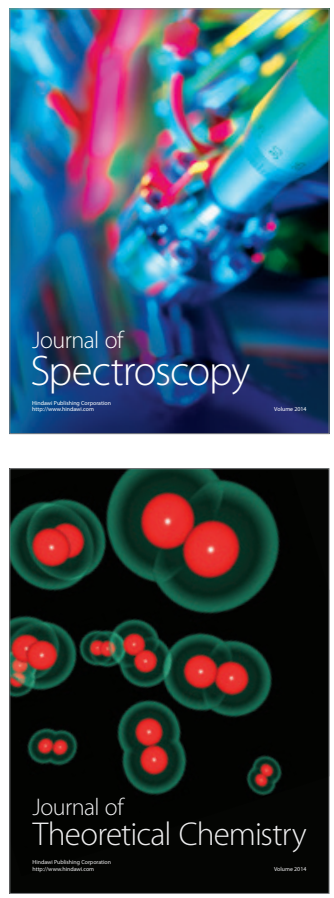
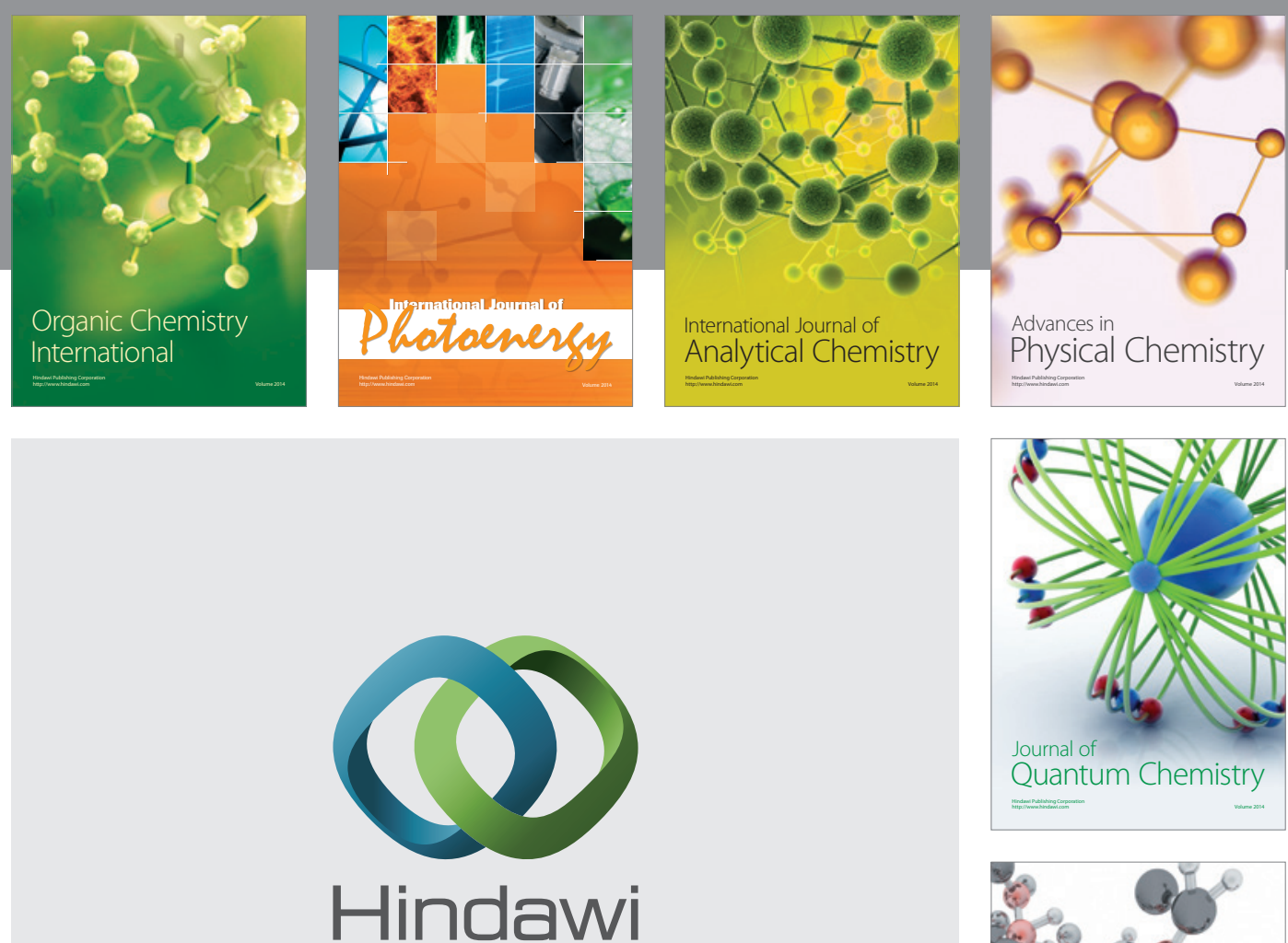

Submit your manuscripts at

http://www.hindawi.com

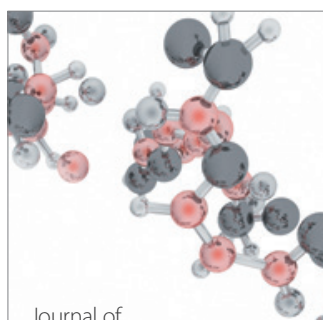

Analytical Methods

in Chemistry

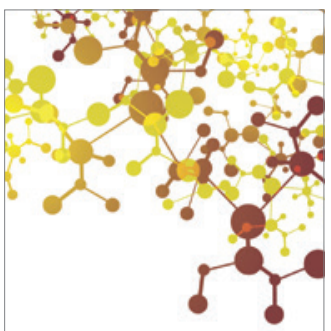

Journal of

Applied Chemistry

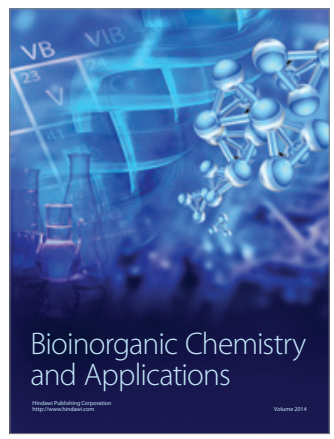

Inorganic Chemistry
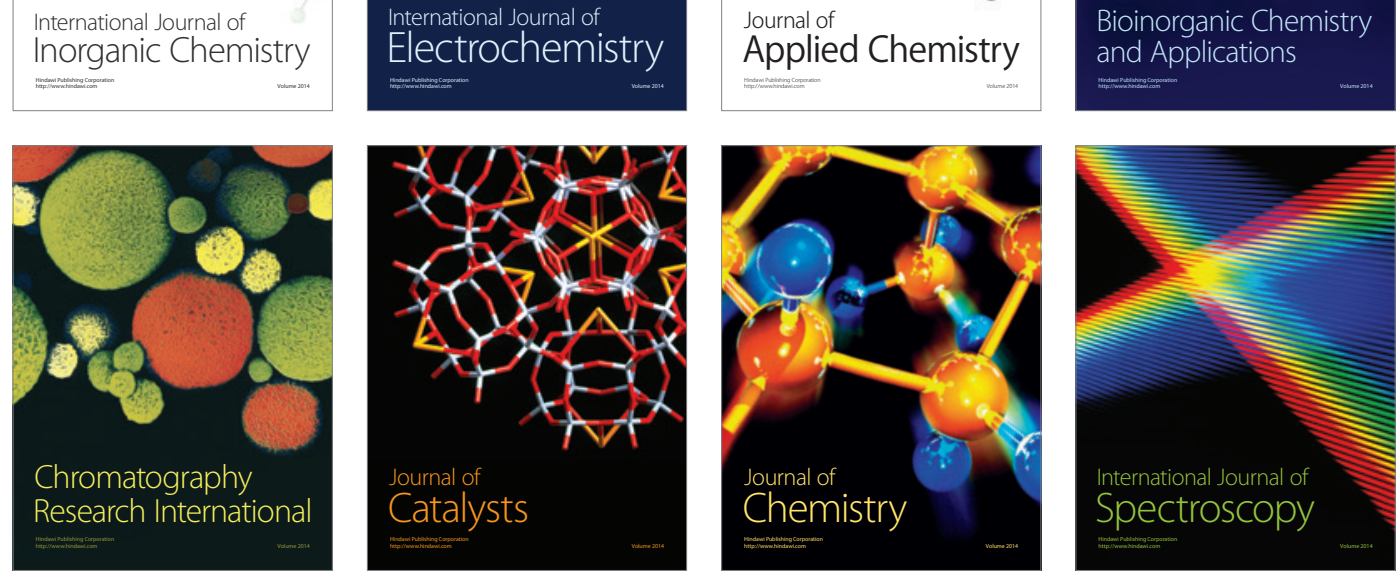